PAPER

\title{
Inhibition of ongoing responses in patients with Parkinson's disease
}

\author{
S Gauggel, M Rieger, T-A Feghoff
}

See end of article for

J Neurol Neurosurg Psychiatry 2004;75:539-544

authors' affiliations

......................

Correspondence to:

S Gauggel, Department of

Psychology, University of

Technology Chemnitz,

Wilhelm-Raabe-Str. 43,

D-09120 Chemnitz,

Germany;

siegfried.gauggel@

phil.tu-chemnitz.de

Received 7 April 2003

In revised form

17 May 2003

Accepted

16 September 2003

\begin{abstract}
Objectives: We investigated the involvement of the basal ganglia in inhibiting ongoing responses in patients with Parkinson's disease (PD).

Methods: Thirty two patients with PD and 31 orthopaedic controls performed the stop signal task, which allows an estimation of the time it takes to inhibit an ongoing reaction (stop signal reaction time, SSRT). Results: Patients with PD showed significantly longer SSRTs than the controls. This effect seemed to be independent of global cognitive impairment and severity of PD. Furthermore, in the PD patients, there was no significant relation between general slowing and inhibitory efficiency.

Conclusions: Our results provide evidence for involvement of the basal ganglia in the inhibition of ongoing responses.
\end{abstract}

$\mathrm{P}$

revious lesion and neuroimaging studies have shown that the frontal lobes, especially the (right) inferior frontal gyrus and the anterior cingulate gyrus, play an important role in response inhibition. ${ }^{1-6}$ Deficits in response inhibition have also been demonstrated after lesions of the basal ganglia ${ }^{5}$ and point to a close relationship between the prefrontal cortex and the basal ganglia ("basal gangliathalamocortical circuits" $).{ }^{8-11}$

Cooper and colleagues, ${ }^{7}$ for example, showed that patients with Parkinson's disease (PD) made more errors in a no-go condition than controls, thus indicating a response inhibition deficit in these patients. Rieger et al were able to demonstrate a significantly longer stop signal response time-reflecting impaired inhibition of ongoing responses-in patients with basal ganglia lesions caused by a cerebrovascular disorder in comparison with an orthopaedic control group. ${ }^{5}$ Converging evidence for the involvement of the basal ganglia (especially the striatum) in response inhibition comes from animal research. Apicella et al investigated the neuronal activity in the striatum in a delayed go/no-go task in monkeys. ${ }^{12}$ About $5 \%$ of the neurones, which showed task-related activity, were specifically activated in the no-go condition, possibly reflecting a behavioural reaction consisting of the inhibition of movement.

Taken together, the findings from the reported studies provide evidence for the critical role of the basal ganglia in response inhibition. Furthermore, the findings support current theoretical models which emphasise the function of the basal ganglia in the choice of motor programmes by activating and inhibiting competing programmes. ${ }^{10}$

However, the role of the basal ganglia in response inhibition has not been studied as intensively as the involvement of the frontal lobe. Therefore, the present study was intended to replicate and extend the previous finding of a response inhibition deficit in patients with basal ganglia lesions. ${ }^{5}$ Patients with idiopathic PD were investigated with the stop signal task, which requires participants to respond to a stimulus ("go" task), but to inhibit their response in some of the trials ("stop" task), thus measuring the ability to cancel an action that is already in progress.
The stop signal task is based on a formal mathematical theory and its particular strength is that it provides a way of measuring inhibition controlling for concurrent differences in the speed and/or variability of responding on the go task which do not reflect core inhibitory control. ${ }^{13}{ }^{14}$ On the basis of findings from a previous study of patients with basal ganglia lesions after a cerebrovascular disorder, we expected to find a significantly prolonged stop signal reaction time (SSRT) in patients with PD in comparison with an age matched clinical control group. ${ }^{5}$

\section{METHODS \\ Participants}

A consecutive series of 32 patients with $\mathrm{PD}$ and 31 orthopaedic patients (controls, OC) took part in this study. Patients with PD were investigated during their stay in a hospital specialising in the treatment and rehabilitation of patients with PD. Orthopaedic patients were selected from another rehabilitation hospital to match the PD patients as closely as possible with regard to age, sex, and years of education. Table 1 provides an overview of the major demographic and clinical characteristics of both groups.

Independent $t$ tests revealed no differences between the two groups in either age $(t=0.72, \mathrm{p}=0.47)$ or years of education $(t=1.41, \mathrm{p}=0.16)$. In both groups all patients were right-handed, with a mean handedness score (SD) of 74.5 (29.1) for the PD patients and 86.5 (31.5) for the controls. ${ }^{15}$ There was no group difference in handedness $(t=-1.57, \mathrm{p}=0.12)$ and all patients used their preferred hand to perform the stop signal task.

All PD patients were receiving medication during time of testing and were taking levodopa, dopamine agonists, anticholinergic drugs, or a combination of levodopa plus an

Abbreviations: AMS, Achievement Measure System; ANCOVA, analysis of covariance; AVLT, Auditory Verbal Learning Test; OC, orthopaedic controls; RT, reaction time; SSRT, stop signal reaction time; $P D$, Parkinson's disease 
Table 1 Demographic and clinical characteristics of patients with Parkinson's disease (PD) and the orthopaedic controls (OC)

\begin{tabular}{|c|c|c|c|c|c|c|c|}
\hline & \multicolumn{4}{|l|}{ Group } & \multirow[b]{3}{*}{$t$} & \multirow[b]{3}{*}{ df } & \multirow[b]{3}{*}{ Effect size (d) } \\
\hline & \multicolumn{2}{|c|}{ PD $\left(17 / 15^{\star}\right)$} & \multicolumn{2}{|c|}{$O C\left(17 / 14^{*}\right)$} & & & \\
\hline & Mean & SD & Mean & SD & & & \\
\hline Age (years) & 57.8 & 5.2 & 56.7 & 7.2 & 0.72 & 61 & 0.18 \\
\hline Education (years) & 10.8 & 1.7 & 10.2 & 1.5 & 1.41 & 61 & 0.37 \\
\hline Laterality quotient & 74.5 & 29.1 & 86.5 & 31.5 & -1.57 & 61 & -0.40 \\
\hline $\begin{array}{l}\text { Time since onset } \\
\text { of illness (weeks) }\end{array}$ & 470 & 282 & & & & & \\
\hline
\end{tabular}

anticholinergic drug. In line with institutional guidelines, all patients gave written informed consent and the ethical committee of the German Society for Psychology approved the experimental design of the study. None of the patients were paid for participating in the study.

\section{Assessment of impairments and activity restrictions}

Assessment of intellectual functioning, memory, executive function, and mood of the patients was carried out to provide an estimate of cognitive impairment. Furthermore, the Hoehn and Yahr staging of $\mathrm{PD}^{16}$ and the Webster Rating Scale $^{17}$ were employed to assess specific PD symptoms and activity restrictions. It was not possible to perform each neuropsychological test with all participants, in particular the controls who had a short stay in hospital and a tight treatment programme. Other reasons why not all patients performed all tests were early discharge and graphomotor deficits. Therefore, the sample size in the PD group varied from 28 to 31 and in the OC group from 18 to 29 .

\section{Intellectual functioning}

Intellectual functions were assessed with a short form ${ }^{18}{ }^{19}$ of the Achievement Measure System (AMS), a commonly used German intelligence test, ${ }^{20}$ which consists of six subtests: vocabulary, abstract reasoning, verbal competence, spatial thinking, visual interference, and word recognition. In addition, the verbal fluency subtest of the AMS was performed because it is a good indicator of executive functions. ${ }^{21}$ For each subtest, T-scores were determined from the standardisation sample of the AMS and used for further analysis.

\section{Memory}

A German version ${ }^{22}$ of the Auditory Verbal Learning Test $(\mathrm{AVLT})^{23}$ was used to assess memory functions. The total score-that is, the sum of correctly remembered words for trials I through V, was used for analysis. Potential scores for the total score range from 0 to 75 .

\section{Concept formation and concept shifting}

A computer version ${ }^{24}$ of the Modified Card Sorting Test, ${ }^{25}$ which is a modified version of the Wisconsin Card Sorting Test, ${ }^{26}$ was used. The percentage of perseverative errors of all errors was used as an index in this study, since it has been frequently shown to be sensitive to executive deficits and frontal lobe lesions, ${ }^{25} 27$ and is interpreted as indicative of inhibition of mental set.

\section{Mood}

In addition, all participants were asked to fill out the Center for Epidemiological Studies-Depression Scale. ${ }^{28}$ Each participant's total score was determined and used for further analysis. Potential scores range from 0 to 60 . Higher scores correspond to higher levels of depression, and a cut-off point of 17 is regarded as a good indicator of a depressive disorder. Table 2 gives an overview of the test scores and effects sizes for both groups.

As can be seen from table 2, Parkinson's disease patients differed significantly from the controls with respect to memory, concept formation and concept shifting, and several intellectual functions (word fluency, space, field dependence, and closure). In addition, they showed significantly more depressive symptoms than OC. This was considered in the analysis and interpretation of the stop signal task results. However, no patient was demented according to DSM-IV criteria. ${ }^{29}$

\section{The stop signal task}

Apparatus and stimuli

The stimuli for the choice reaction time (RT) task were a black square $(2.5 \mathrm{~cm}$ side length) and a black circle $(2.8 \mathrm{~cm}$ diameter). The participants were seated approximately $50 \mathrm{~cm}$ in front of a computer screen (VGA, $38.1 \mathrm{~cm}$ ). The stop signal was a $1000 \mathrm{~Hz}$ tone of $500 \mathrm{~ms}$ duration, presented through the internal speaker to headphones. Participants responded by pressing one of two reaction buttons with the middle finger and forefinger of their preferred hand.

\section{Design and procedure}

The choice task involved discriminating the black square and the black circle, which were randomly assigned to the left and right response buttons. Each trial began with the presentation of four small squares $(0.5 \mathrm{~cm}$ side length), which moved from the corners of the screen to the centre in a fixed interval of $500 \mathrm{~ms}$ for fixation. This was done to capture and focus the attention of the participants. Immediately thereafter the primary task stimulus (square or circle) appeared. It disappeared as soon as participants pressed one of the two response buttons. In case participants did not respond the stimulus remained for $2500 \mathrm{~ms}$. After an interval of $1000 \mathrm{~ms}$ during which the screen remained blank the next trial started. The stop signal was presented on $25 \%$ of the trials.

The stop signal delay was set by a staircase tracking algorithm, ${ }^{30}$ which adapts to the response rate. We employed one staircase to adjust the delay in a way that participants could inhibit approximately $50 \%$ of all stop trials. This is done the following way: if in a trial with stop signal the response is not inhibited, the delay is reduced by $50 \mathrm{~ms}$ the next time a stop signal occurs, thus increasing the chance of successful inhibition. Successful inhibition is followed by an increase of the delay by $50 \mathrm{~ms}$ in the next stop signal trial, which makes it harder to inhibit the response. As a result approximately $50 \%$ of all responses are stopped. At the beginning the delay 


\begin{tabular}{|c|c|c|c|c|c|c|c|c|c|c|}
\hline & \multicolumn{6}{|l|}{ Group } & \multirow[b]{3}{*}{$t$} & \multirow[b]{3}{*}{ df } & \multirow[b]{3}{*}{ Effect size (d) } & \multirow[b]{3}{*}{$\mathbf{p}$} \\
\hline & \multicolumn{3}{|l|}{ PD } & \multicolumn{3}{|l|}{ OC } & & & & \\
\hline & Mean & SD & n & Mean & SD & $\mathbf{n}$ & & & & \\
\hline \multicolumn{11}{|l|}{ Achievement Measure } \\
\hline Vocabulary & 45.7 & 9.9 & 29 & 49.3 & 10.8 & 18 & -1.18 & 45 & -0.35 & 0.24 \\
\hline Abstract reasoning & 49.7 & 9.9 & 29 & 52.8 & 9.1 & 18 & -1.11 & 45 & -0.32 & 0.28 \\
\hline Verbal competence & 51.6 & 8.8 & 28 & 57.7 & 10.0 & 18 & -2.17 & 44 & -0.66 & 0.04 \\
\hline Word fluency & 61.5 & 10.7 & 30 & 56.9 & 10.2 & 29 & 1.67 & 57 & 0.44 & 0.10 \\
\hline Spatial thinking & 48.3 & 9.9 & 29 & 55.7 & 7.4 & 18 & -2.71 & 45 & -0.82 & 0.01 \\
\hline Visual interference & 49.3 & 7.8 & 30 & 58.0 & 6.3 & 24 & -4.43 & 52 & -1.21 & 0.001 \\
\hline Word recognition & 43.3 & 11.2 & 29 & 53.1 & 10.1 & 18 & -3.03 & 45 & -0.91 & 0.01 \\
\hline Modified Card & & & & & & & & & & \\
\hline \multicolumn{11}{|l|}{ Sorting Test } \\
\hline Perseverative errors (\%) & 25.1 & 15.5 & 31 & 15.4 & 18.4 & 28 & 2.18 & 57 & 0.57 & 0.03 \\
\hline AVLT (total score) & 43.2 & 8.9 & 30 & 48.5 & 8.1 & 27 & -2.34 & 55 & -0.62 & 0.02 \\
\hline Depression scale & 19.7 & 7.6 & 30 & 12.9 & 8.5 & 25 & 3.14 & 53 & 0.89 & 0.01 \\
\hline Webster Rating Scale & 9.1 & 4.3 & 32 & & & & & & & \\
\hline Hoehn and Yahr staging & 2.6 & 0.8 & 28 & & & & & & & \\
\hline
\end{tabular}

AVLT, Auditory Verbal Learning Test; Depression scale, Center of Epidemiological Studies-Depression Scale; SD, standard deviation; df, degrees of freedom; $t$, independent $t$ test.

of the first stop signal is set at $200 \mathrm{~ms}$. After a period of adjustment, the delay varies around values that are most informative, and the mean delay can subsequently be used for further calculations.

This procedure inherently corrects for individual and group differences in the RT distribution and for the tendency to postpone responses. It provides a way of measuring inhibition (SSRT) by controlling for differences in speed of responding to the go signal. This is important, because slower response execution processes are easier to stop than faster ones at equivalent delays. Because PD may affect the speed of the response execution process, $^{3132}$ the ability to disentangle the effects of the response execution process on the inhibition process is of importance. An additional advantage of the tracking procedure is that the response rates remain almost constant across groups, despite differences in the efficiency of inhibitory control.

Participants were tested in one session which lasted approximately $45 \mathrm{~min}$. They performed two practice blocks and 10 experimental blocks. In the first practice block (60 trials), participants had to perform the choice RT task alone, in the second practice block (40 trials), the stop signal was added. After that, participants performed 10 experimental blocks, each consisting of 40 trials (30 no signal trials and 10 stop signal trials). The importance of responding as fast as possible to the choice RT task was emphasised in the instructions. Participants were told to respond quickly while maintaining a high level of accuracy. They were instructed not to delay their responses in anticipation of the stop signal but to make a concerted effort to withhold the response if they detected the stop signal. It was explained to them that they would not always be able to withhold the response and that the computer would adjust to their efficiency, yielding approximately a $50 \%$ success rate.

The SSRT was estimated by calculating the difference between the average RT on trials without stop signal and the average stop signal delay. Average RT on trials without stop signal, RT where the subjects responded in spite of the stop signal, percentage of errors, and probability of responding were further dependent variables. In addition, the last 40 trials of the first exercise block without stop signal were calculated as an estimation of primary task response speed, since RT in the experimental blocks might be influenced by task complexity and the tendency to postpone responses. ${ }^{33}{ }^{34}$ For a detailed description of the stop signal task and its mathematical formulation see Logan. ${ }^{14}$

\section{Statistical analysis}

All data were screened for deviation from normality, outliers, and homogeneity of variance, and assumptions for statistical analysis were proved..$^{35}$ Group comparisons and comparisons between conditions were carried out using independent $t$ tests (2-tailed) and analysis of variance (ANOVA). In addition an ANCOVA (analysis of covariance) was performed to control for differences in primary reaction time. Effect sizes were calculated according to Cohen (d). ${ }^{36}$

\section{RESULTS}

Results of the stop signal task are presented in table 3.

The probability of responding did not differ between the two groups $(48.1 \%$ and $47.1 \%)$, which shows that the staircase tracking algorithm was successfully applied to equalise response rates between both groups. This is a necessary prerequisite for the interpretation of the results. There were significant group differences in the error rate and in the SSRT indicating that PD patients made more errors and were much slower in inhibiting the ongoing response than the controls. In addition, there was also a significant group difference in primary RT of the practice block where no stop signal was presented.

There was no significant group difference in primary task RTs of the experimental blocks where go and stop trials were randomly presented, presumably because a tendency to postpone responses levelled differences between the groups. As can be seen from table 3, primary task RTs were longer in the experimental blocks with the stop signal than in the exercise block. A $2 \times 2($ Group $\times$ Block) ANOVA with Block (RT in the exercise block and RT in the experimental block) as a repeated factor revealed a significant main effect for Group $\left(F_{3,58}=3.89, \mathrm{p}=0.01\right)$ and a significant main effect for Block $\left(F_{1,58}=39.74, \mathrm{p}<0.0001\right)$. The interaction Group $\times$ Block, however, was not significant $\left(F_{3,58}=0.99, \mathrm{p}=0.40\right)$. Thus, there was a strong tendency for both groups to have longer 
Table 3 Results of the stop signal task for patients with Parkinson's disease (PD) and orthopaedic controls (OC)

\begin{tabular}{|c|c|c|c|c|c|c|c|}
\hline & \multicolumn{4}{|l|}{ Group } & \multirow[b]{3}{*}{$t(\mathrm{df}=61)$} & \multirow[b]{3}{*}{ Effect size (d) } & \multirow[b]{3}{*}{ p } \\
\hline & \multicolumn{2}{|l|}{ PD } & \multicolumn{2}{|l|}{ OC } & & & \\
\hline & Mean & SD & Mean & SD & & & \\
\hline RT (practice block) & 595 & 84 & 545 & 55 & 2.81 & 0.70 & 0.007 \\
\hline Probability of responding & 48.1 & 3.6 & 47.1 & 2.9 & 1.26 & 0.31 & 0.2 \\
\hline Errors \% & 8.1 & 9.8 & 3.9 & 5.2 & 2.11 & 0.53 & 0.04 \\
\hline RT in trials without stop signal & 769 & 189 & 767 & 217 & 0.04 & 0.01 & 0.97 \\
\hline Signal respond RT (ms) & 675 & 142 & 675 & 184 & -0.01 & 0.00 & 0.99 \\
\hline SSRT (ms) & 330 & 63 & 259 & 58 & 4.63 & 1.17 & 0.0001 \\
\hline
\end{tabular}

RTs in the experimental blocks, but there was no indication that any group performed different in this respect. However, because of the effect of longer RTs in the experimental blocks, RTs in the exercise block will be interpreted as the general speed of responding.

\section{Inhibition and general slowing}

To investigate whether the effect of longer SSRTs might be due to an effect of general slowing in the PD group, Pearson's product moment correlation between SSRT and practice block RT (the last 40 trials of the first exercise block without stop signal) were calculated (OC: $r=0.40, \mathrm{p}=0.018$; PD: $r=0.20, \mathrm{p}=0.35)$. Those correlations indicate that the association between response inhibition and initiation is low (4-16\% of the variance is explained) and are not significantly different from each other (Fisher's z test).

In addition, an ANCOVA (analysis of covariance) with practice block RT (the last 40 trials of the first exercise block without stop signal) as a covariate was performed. Requirements for performing an ANCOVA were fulfilled. The regression slopes were sufficiently homogeneous $\left(F_{1,59}=2.18, \mathrm{p}=0.14\right)$ and there was a linear relationship between SSRT and practice block RT for the combined groups $(r=0.39, \mathrm{p}<0.002)$ although this relationship is low. An ANCOVA revealed a highly significant group effect $\left(F_{1,60}=13.55, \quad \mathrm{p}=0.0005\right)$. Adjusted means for SSRT $(\mathrm{PD}=324 \mathrm{~ms} ; \mathrm{OC}=265 \mathrm{~ms})$ indicated that the $\mathrm{PD}$ group had significantly slower SSRTs than the OC group even after controlling for differences in primary reaction time.

\section{PD symptoms and neuropsychological test performance}

We were also interested in determining whether symptom severity and overall cognitive abilities of the PD patients were associated with their inhibitory efficiency assessed by the stop signal task. To do this, we conducted two multiple regression analyses in which clinical/sociodemographic variables were used in the first and cognitive variables in the second analysis. Predictors were selected a priori and should lead to two prediction models (one model for the cognitive and one for the clinical/sociodemographic domain). The dependent variable in both regression analyses was SSRT. Only those variables were selected as predictors which can be regarded as the best indicator of the measured function-for example, total score in the AVLT. For the first multiple regression analysis we chose the following independent variables:

- the Webster Rating Scale score

- age, and

- Center of Epidemiological Studies-Depression Scale score.
Independent variables for the second multiple regression analysis were:

- percentage of perseverative errors of all errors in the Wilsconsin Card Sorting Test

- total score of the AVLT, and

- the combined score of the AMS.

Due to missing values sample size was 29 for the first analysis and 28 for the second analysis.

Only the first multiple regression analysis revealed a significant finding $\left(F_{3,26}=7.29, \quad \mathrm{p}=0.001, \quad R^{2}=0.46\right)$. Reliable predictors of this effect were age (beta $=4.2$, $t(26)=2.28, \mathrm{p}=0.03)$ and depression score (beta $=4.3$, $t(26)=3.32, \mathrm{p}=0.003)$. These relationships indicated that those PD patients who showed longer SSRTs also tended to have higher depression scores and tended to be older.

\section{DISCUSSION}

In the present study patients with PD in the mild-moderate stages of illness (mainly Hoehn and Yahr stages I-III) were compared with age matched orthopaedic controls on the stop signal task to investigate response inhibition. We found a significantly longer SSRT (a sensitive estimate of inhibitory control), in PD patients compared to the clinical control group. However, patients with PD did not only show an impairment in response inhibition but also an expected deficit in response initiation. ${ }^{32}$ In addition, PD patients performed worse than OC in several neuropsychological tests which have been shown sensitive to the neuropathology of PD. ${ }^{37}$

Although patients with PD did not only show a response inhibition deficit but also other cognitive impairments and a general slowing we think that there are several arguments which support the interpretation of an inhibitory control deficit in these patients. Firstly, the group difference was still obvious after compensating for differences in primary task RT by an ANCOVA, the estimate for SSRT in the PD group was still $59 \mathrm{~ms}$ higher than for the OC group. Furthermore, there was no significant correlation of SSRT and practice block RT within PD patients. This is actually surprising, since previous studies have found that RT can explain some but by no means all of the variance of SSRT. The correlation of SSRT and primary task RT within the controls fits well with previous studies which have shown that initiation speed can explain some, but not all, of the variance of inhibition speed in different age groups ${ }^{38}$ and brain-damaged patients. ${ }^{5}$ Although the correlation of SSRT and RT was not significant in the PD patients, it was also not significantly different from that of the OC group. Thus, we cannot draw any definite conclusions whether PD patients show more independence of initiation and inhibition than healthy persons. 
Secondly, regression analysis indicated that cognitive impairments were not reliable predictors of inhibitory efficiency. Only severity of depression and age were associated with efficiency of response inhibition.

The findings of our study correspond with the results of Rieger et al, ${ }^{5}$ who investigated patients with cerebrovascular lesions with the stop signal task, the study of Cooper et al, who showed that patients with PD made more errors in a nogo condition than controls and with Apicella et al, ${ }^{12}$ who found neurones in the striatum in monkeys, which were specifically activated in a no-go condition. Furthermore, van den Wildenberg found that high-frequency deep brain stimulation of the subthalamic nucleus but not stimulation of the ventral intermedius nucleus led to an improvement of stop signal inhibition. ${ }^{39}$

From a theoretical perspective, our findings agree with the proposition of Band and van Boxtel, that the prefrontal cortex and the basal ganglia are candidate agents for response inhibition in the stop signal task. ${ }^{40}$ The conception of an inhibition system with the "basal gangliathalamocortical circuits" at its basis could conceivably help to explain the findings of the present study. Damage to such circuits fits neatly with the kind of difficulty observed in the present study in which PD patients had to intentionally inhibit an ongoing response. One can speculate that the response inhibition deficit in PD patients is caused primarily by a degeneration of melanin-containing, dopaminergic neurones of the substantia nigra pars compacta and subsequent functional changes in the "basal gangliathalamocortical circuits" ${ }^{41}$

In summary, PD patients showed significantly longer times to inhibit an ongoing response than orthopaedic patients. This deficit in response inhibition was pronounced and independent of general slowing and cognitive impairment. Future studies should compare different lesions within the basal ganglia to get a more detailed neuroanatomical assignment of inhibition of ongoing responses. In addition, neuropharmacological interventions or pallidal deep brain stimulation could deliver further evidence about the neural implementation of inhibitory control mechanisms and the role of the basal ganglia.

\section{ACKNOWLEDGEMENTS}

We thank the staff of the Elena Hospital in Kassel for their kind support. Funding for this research was provided to the first author through a grant from the German Research Foundation (RO 529/12-1).

\section{Authors' affiliations}

S Gauggel, Department of Psychology, University of Technology

Chemnitz, Chemnitz, Germany

M Rieger, Max Planck Institute for Psychological Research, Munich

T-A Feghoff, Sturkamp 9, D-22081 Hamburg

Competing interests: none declared

\section{REFERENCES}

1 Aron AR, Fletcher PC, Bullmore ET, et al. Stop-signal inhibition disrupted by damage to right inferior frontal gyrus in humans. Nat Neurosci 2003;6:115-16.

2 Garavan H, Ross TJ, Stein EA. Right hemispheric dominance of inhibitory control: an event-related functional MRI study. Proc Natl Acad Sci U S A 1999;96:8301-6.

3 Kawashima R, Satoh K, Itoh $\mathrm{H}$, et al. Functional anatomy of GO/NO-GO discrimination and response selection - a PET study in man. Brain Res 1996;728:79-89.

4 Konishi S, Nakajima K, Uchida I, et al. Common inhibitory mechanism in human inferior prefrontal cortex revealed by event-related functional MRI. Brain 1999; 122:981-91.

5 Rieger M, Gauggel S, Burmeister K. The role of the frontal lobes and the basal ganglia in the inhibition of ongoing responses. Neuropsychology 2003; 17:272-82.

6 Rubia K, Russell T, Overmeyer S, et al. Mapping motor inhibition: conjunctive brain activations across different versions of go/no-go and stop tasks. Neuroimage 2003;13:250-61.
7 Cooper JA, Sagar HJ, Tidswell P, et al. Slowed central processing in simple and go/no-go reaction time tasks in Parkinson's disease. Brain 1994; 117:517-29.

8 Alexander GE, Crutcher MD, DeLong MR. Basal ganglia-thalamocortical circuits: parallel substrates for motor, oculomotor, "prefrontal" and "limbic" functions. Prog Brain Res 1990;85:119-46.

9 Kropotov JD, Etlinger SC. Selection of actions in the basal gangliathalamocortical circuits: review and model. Int J Psychophysiol 1999;31:197-217.

10 Mink JW. The basal ganglia: focused selection and inhibition of competing motor programs. Prog Neurobiol 1996;50:381-425.

11 Wichmann T, DeLong MR. Functional and pathophysiological models of the basal ganglia. Curr Opin Neurobiol 1996;6:751-8.

12 Apicella P, Scarnati E, Liungberg T, et al. Neuronal activity in monkey striatum related to the expectation of predictable environmental events. J Neurophysiol 1992;68:945-60.

13 Band GPH, van der Molen MW, Logan GD. Horse-race model simulations of the stop-signal procedure. Acta Psychologica 2003;112:105-42.

14 Logan GD. On the ability to inhibit thought and action: a users' guide to the stop signal paradigm. In: Dagenbach D, Carr TH, eds. Inhibitory Processes in Attention, Memory and Language. San Diego: Academic Press, 1994:189-239.

15 Oldfield RC. The assessment and analysis of handedness: the Edinburgh inventory. Neuropsychologia 1971;9:97-113.

16 Hoehn MM, Yahr MD. Parkinsonism: onset, progression and mortality. Neurology 1967; 17:427-42.

17 Webster DD. Critical analysis of the disability in Parkinson's disease. Mod Treat 1968:5:257-82.

18 Sturm W, Willmes K. LPS-K-eine LPS-Kurzform für Hirngeschädigte Patienten; mit Anleitungen zur psychometrischen Einzelfalldiagnostik. [LPS-Ka short form of the Leistungspruefsystem for brain damaged patients with instructions for psychometric single case diagnosis.] Diagnostica 1983;29:346-58.

19 Sturm W, Willmes K, Horn W. Leistungsprüfsystem für 50-90iährige (LPS 50+).[Achievement Measure for 50- to 90-Year-Olds.]. Göttingen: Hogrefe, 1993.

20 Horn W. Leistungsprüfsystem LPS. [Achievement Measure System.]. Göttingen: Hogrefe, 1983.

21 Baldo JV, Shimamura AP. Letter and category fluency in patients with frontal lobe lesions. Neuropsychology 1998;12:259-67.

22 Heubrock D. Der Auditiv-Verbale Lerntest (AVLT) in der klinischen und experimentellen Neuropsychologie. Durchfuehrung, Auswertung und Forschungsergebnisse.[The Auditiv-Verbaler Lerntest (AVLT), a German version of the Auditory-Verbal Learning Test, in clinical and experimental neuropsychology.] Z Different Diagnost Psychol 1992;13:161-74.

23 Lezak MD. Neuropsychological assessment. New York: Oxford University Press, 1995.

24 Truong MK. Short Wisconsin Card Sorting Test nach Nelson 1976, Version 1.1. Wuppertal: Universität-GHS Wuppertal, Klinische Psychologie, 1993.

25 Nelson HE. A modified card sorting test sensitive to frontal lobe defects. Cortex 1976;12:313-24.

26 Milner B. Some effects of frontal lobectomy in man. In: Warren JM, Akert K, eds. The frontal granular cortex and behavior. New York: McGraw-Hill, 1964:313-34.

27 Berry EL, Nicolson RI, Foster JK, et al. Slowing of reaction time in Parkinson's disease: the involvement of the frontal lobes. Neuropsychologia 1999;37:787-95.

28 Radloff LS. The CES-D scale: a self report Major Depressive Disorder scale for research in the general population. Appl Psychol Measurement 1977;1:385-401.

29 American Psychiatric Association. Diagnostic and Statistical Manual of Mental Disorders, 4th edn. Washington, DC: American Psychiatric Association, 1994.

30 Kaernbach C. Simple adaptive testing with the weighted up down method. Percept Psychophys 1991;49:227-9.

31 Gauntlett-Gilbert J, Brown VJ. Reaction time deficits and Parkinson's disease. Neurosci Biobehav Rev 1998;22:865-81

32 Wang J, Thomas JR, Stelmach GE. A meta-analysis on cognitive slowing in Parkinson's disease: are simple and choice reaction times differentially impaired? Parkinsonism Relat Disord 1998;4:17-29.

33 Logan GD. Attention, automaticity, and the ability to stop a speeded choice response. In: Long J, Baddeley A, eds. Attention and Performance IX. Hillsdale: Erlbaum, 1981:205-22.

34 McGarry T, Franks IM. A horse race between independent processes: evidence for a phantom point of no return in the preparation of a speeded motor response. J Exp Psychol Hum Percept Perform 1997;23:1533-42.

35 Tabachnick BG, Fidell LS. Using multivariate statistics, 3rd edn. New York: Harper Collins College Publishers, 1996.

36 Cohen J. Statistical power analysis for the behavioral sciences, 2nd edn. Hillsdale, New Jersey: Lawrence Erlbaum, 1988

37 Taylor AE, Saint-Cyr JA. The neuropsychology of Parkinson's disease. Brain Cogn 1995;28:281-96.

38 Williams BR, Ponesse JS, Schachar RJ, et al. Development of inhibitory control across the life span. Dev Psychol 1999;35:205-13.

39 van den Wildenberg W. Neuro-stimulation of the subthalamic nucleus, but not the thalamus, facilitates response inhibition in patients with Parkinson's disease. In: van den Wildenberg W, ed. Perspectives on stopping behavior: Process analyses of stop-signal inhibition. Amsterdam: University of Amsterdam. www.wery.dds.nl/(last accessed 16 Jan 2004). 
40 Band GPH, van Boxtel GJM. Inhibitory motor control in stop paradigms: review and reinterpretation of neural mechanisms. Acta Psychol 1999; 101:179-211.
41 Blandini F, Nappi G, Tassorelli C, et al. Functional changes of the basal ganglia circuitry in Parkinson's disease. Prog Neurobiol 2000;62:63-88

\section{HISTORICAL NOTE}

\section{Sir Charles Scott Sherrington (1857-1952) and the synapse}

F ulton compared Sherrington's The integrative action of the nervous system to Harvey's De Motu Cordis, while Walshe compared it to Newton's Principia. It is rare for great scholars to proffer such encomiums.

In 1893 Sherrington had coined the term "proprioceptive". By 1900, his research permitted him to conclude that the cerebellum is the head ganglion of the proprioceptive system. In 1898 he described and elucidated decerebrate rigidity in the cat. Years later he discovered and analysed the stretch reflex. Each of these major contributions was a fundamental, original advance.

In The integrative action of the nervous system, ${ }^{1}$ Sherrington introduced a further new concept. ${ }^{2}$ He elucidated the synapse, a nexus for reflex-arc function, the neurone theory, and synaptic transmission. However, Hans Held, in 1897, the year Sherrington introduced the term synapse, had described:

"For the time being the nerve cells zones of transfer appear histological as mainly variable and variously constituted pathways between concrescing surfaces that I shall designate physiologically simply as zones for the transmission of stimuli." ${ }^{\prime 3}$

\section{In his text Sherrington wrote:}

"...At the nexus between cells if there be not actual confluence, there must be a surface of separation. At the nexus between efferent neurone and the muscle cell, electrical organ, etc., which it innervates, it is generally admitted that there is not actual confluence of the two cells together, but that a surface separates them; and a surface of separation is physically a membrane. As regards a number of the features enumerated above as distinguishing reflex-arc conduction from nerve-trunk conduction, there is evidence that similar features, though not usually in such marked extent, characterize conduction from efferent nerve fibre to efferent rent organ, e.g., in nervemuscle preparation, in nerve-electric-organ preparation, etc. Here change in character of conduction is not due to perikarya (nerve-cell bodies), for such are not present. The change may well be referable to the surface of separation admittedly existent between efferent neurone and effector cell.

If the conductive element of the neurone be fluid, and if at the nexus between neurone and neurone there does not exist actual confluence of the conductive part of one cell with the conductive part of the other, ... there must be a surface of separation. Even should a membrane visible to the microscope not appear, the mere fact of nonconfluence of the one with the other implies the existence of a surface of separation. Such a surface might restrain diffusion, bank up osmotic pressure, restrict the movement of ions, accumulate electric charges, support a double electric layer, alter in shape and surface-tension with changes in difference of ... it would be a mechanism where nervous conduction, especially if predominantly physical in nature, might have grafted upon it characters just such as those differentiating reflex-arc conduction from nerve-trunk conduction Against the likelihood of nervous conduction being preeminently a chemical rather than a physical I process must be reckoned, as Macdonald well urges, its speed of propagation, its brevity of timerelations, its freedom from perceptible temperature change, its facile excitation by mechanical means, its facilitation by cold, etc. If it is a physical processes the intercalation of a transverse surface of separation or membrane into the conductor must modify the conduction and it would do so with results just such as we find differentiating reflex-arc conduction from nerve-trunk conduction.

"... vertebrate histology on the whole furnishes evidence that a surface of separation does exist between neurone and neurone. ... It seems therefore likely that the nexus between neurone and neurone in the reflex arc, at least in the spinal arc of the vertebrate, involves a surface of separation between neurone and neurone; and this as a transverse membrane across the conductor must be an important element in intercellular conduction. The characters distinguishing reflex-arc conduction from nervetrunk conduction may therefore be largely due to intercellular barriers, delicate transverse membranes, in the former.

In view, therefore, of the probable importance physiologically of this mode of nexus between neurone and neurone it is convenient to have a term for it. The term introduced has been synapse. ${ }^{\prime 4}$

Charles Scott Sherrington ${ }^{5}$ was born in London in November 1857. He read medicine at Cambridge where Michael Forster, Langley, and Gaskell stimulated his interest in physiology. He graduated from St Thomas' in 1885 and began a series of superbly, original experiments in physiology, which led to the Chair at Liverpool in 1895, succeeded by the Waynflete Chair of Physiology at Oxford in 1913. His extensive studies on neurophysiology ${ }^{6}$ Granit rated as "probably greater than any other person".

In1932, Sherrington shared the Nobel Prize with Edgar Douglas Adrian for work on the function of neurones. He bravely endured painful arthritis, and died on 4 March 1952.

J M S Pearce J M S Pearce, 304 Beverley Road Anlaby, East Yorks HU10 7BG, UK; imspearce@freenet.co.uk

\section{References}

1 Sherrington CS. The integrative action of the nervous system. Charles Scribner's Sons: New York, 1906.

2 Swazey JP. Reflex and motor integration. Sherrington's concept of integrative action. Cambridge Mass: Harvard University Press, 1969

3 Held H. Beiträge zur Structur der Nervenzellen und ihrere Fortsätze. Zweite Abhandlung. Arch Anat physiol (Anat Abt) 204-94.

4 Sherrington CS. The integrative action of the nervous system, pp 16-18 Cited by: Clarke E, and O'Malley CD. The Human Brain and Spinal Cord: A Historical Study. 2nd edn. San Francisco: Norman, 1996:239-40.

5 Eccles JC, Gibson WC. Sherrington, his life and thought. Heidleberg: Springer, 1979.

6 Granit R. Interactions between Pavlov and Sherrington. Trends in Neuroscience 1982;5:182-6. 